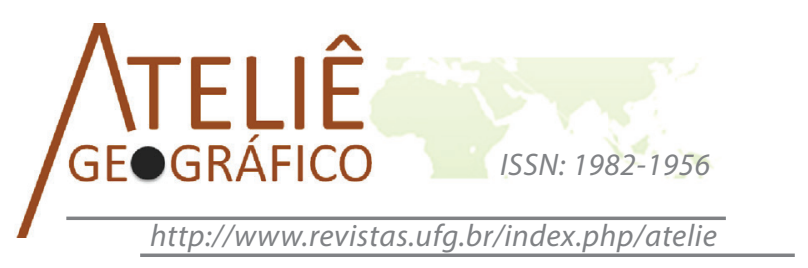

\title{
Avaliação da área de disposição final de resíduos sólidos no município de Goiânia - GO
}

\author{
Assessment of area of final disposal of solid Waste in the \\ city of Goiânia-GO
}

\section{Evaluación de un vertedero de residuos sólidos en el municipio Goiânia-GO}

\author{
Ana Karolyna Nunes Amaral \\ Universidade Federal de Goiás \\ karocana@hotmail.com \\ Frederick Douglas Rodrigues Costa \\ Universidade Federal de Goiás \\ frederick1douglas@gmail.com \\ Noely Vicente Ribeiro \\ Universidade Federal de Goiás \\ noely.ribeiro@uol.com.br
}

\begin{abstract}
Resumo
A correta disposição final de resíduos sólidos urbanos tem sido uns dos principais desafios encontrados pelos governantes do território brasileiro nas últimas décadas. Devido as pressões por parte do governo federal, os lixões estão em processo de extinção e estes vêm sendo substituídos por aterros sanitários, que é a forma ambientalmente mais adequada de dispor os resíduos. Porém, o funcionamento e a operacionalidade dos aterros sanitários deixam a desejar em alguns aspectos se observadas as exigências legais. O presente trabalho teve por objetivo, avaliar a adequabilidade da disposição dos resíduos sólidos na cidade de Goiânia - GO. O método utilizado para realizar, avaliação foi o Índice de Qualidade de Aterro de Resíduos (IQR). O resultado final da classificação do aterro foi de 6,00 encontrandose em condições inadequadas de atuação.

Palavras-Chave: Aterro Sanitário. Lixo. Índice de Qualidade de Aterro de Resíduos. Impacto Ambiental.
\end{abstract}




\begin{abstract}
The correct final disposition of urban solid waste has been one of the main challenges that were found by the government of the Brazilian territory in the last decades. Due to the pressure by the federal government, the garbage dumps are in the process of extinction and they have substituted by sanitary embankments, which are a better way to waste disposition. However, the working and operation of the sanitary embankments have a lack of fulfillment of the legal requirements. This work has the objective of evaluate the better way of sanitary waste disposition on the Goiania-GO city, using like an instrument of evaluation the Index of Quality of Waste Landfill (IQR). The result of the embankment classification was 6,00, which was found inadequate.

Keywords: Sanitary Embankment, Trash, Index of Quality of Waste Landfill, Environmental Impact.

Resumen

La correcta disposición final de residuos urbanos ha sido uno de los principales desafíos encontrados por los gobernantes del territorio brasileño en las últimas décadas. Debido a las presiones por parte del gobierno federal, los basureros están en proceso de extinción y estos han sido sustituidos por terraplenes sanitarios, lo cual es una forma ambientalmente más adecuada de disposición de residuos. Sin embargo, el funcionamiento y operación de los terraplenes sanitarios no siempre cumplen, en algunos aspectos, las exigencias legales. El presente trabajo tiene por objetivo evaluar la forma más adecuada de la disposición de residuos sanitarios en la ciudad de Goiânia-GO, utilizando como instrumento de evaluación el Índice de Calidad de Terraplén de Residuos (IQR). El resultado final de la clasificación del terraplén fue de 6,00 el cual se encuentra en condiciones inadecuadas de operación. Palabras clave: Terraplén Sanitário, Basura, Índice de Calidad de Terraplén de Residuos, Impacto Ambiental.
\end{abstract}

\title{
Introdução
}

As montanhas de lixo geradas todos os dias devem ser destinadas a algum lugar, e a partir daí tem-se início um grande problema, pois, a maioria das cidades brasileiras não tratam de maneira adequada os resíduos gerados pela população. Em 2008, apenas 1.092 dos 5.564 municípios brasileiros tinham aterros sanitários, de acordo com os levantamentos feitos pelo Ministério do Meio Ambiente (MMA) em 2014, esse número aumentou razoavelmente para 2.205 municípios.

Esse aumento deve-se à Política Nacional de Resíduos Sólidos (PNRS) sancionada pela Lei 12.305 em 2010, que obrigou todos os municípios a criarem um plano de gestão de resíduos sólidos, para terem acesso a recursos financeiros do governo federal, onde até o ano de 2014 o Brasil não poderia ter seus lixões em funcionamento, sendo os mesmos substituídos pelos aterros sanitários. O prazo foi finalizado, entretanto, menos de $50 \%$ dos municípios brasileiros conseguiram executar seus planos e alguns nem chegaram a apresentá-los (MMA, 2014). 
De acordo com a NBR 10.004 da ABNT (Associação Brasileira de Normas Técnicas), existem três formas adotadas pela sociedade urbana para a disposição dos resíduos sólidos, sendo o lixão, aterro controlado e aterro sanitário.

Os lixões ou vazadouros, são caracterizados pela descarga a céu aberto, sem qualquer estudo na área "escolhida". Não levando em consideração a percolação dos líquidos derivados da decomposição do lixo, a liberação de gases para atmosfera e a proliferação de insetos, roedores e outros animais que podem transmitir doenças (MUÑOZ, 2002, pg.8). Neste também não há o controle da entrada de catadores, animais e possibilitando ainda mais a contaminação.

Já o aterro controlado se diferencia dos lixões, uma vez que recebe uma camada de solo diariamente, evitando-se assim a contaminação do ambiente externo, mas não havendo o devido cuidado com os demais vetores. Segundo Araújo (2014, pg.38), aterro controlado, pode ser definido como uma forma de se confinar tecnicamente o lixo coletado sem poluir o ambiente externo, porém, não promove a coleta e o tratamento do chorume e do biogás.

O aterro sanitário conforme Elk (2007, pg.13), é uma obra de engenharia projetada sob critérios técnicos, cuja finalidade é garantir a disposição final dos resíduos sólidos sem causar danos à saúde pública e ao meio ambiente. O Ministério Público de Goiás (2009) define os aterros sanitários como sendo espaços preparados para receber e acondicionar adequadamente os resíduos sólidos urbanos e além de proporcionar cobertura diária do lixo, o aterro sanitário é preparado para tratar o chorume e queimar os gases gerados pela decomposição dos resíduos sólidos. "A operação de um aterro deve ser precedida do processo de seleção de áreas, licenciamento, projeto executivo e implantação" (MONTEIRO et al, 2001, pg.145- 151).

Segundo a Associação Brasileira de Empresas de Limpeza Pública e Resíduos Especiais (ALBRELPE) em 2014, aproximadamente 40\% dos resíduos produzidos no Brasil foram destinados aos aterros sanitários, $32 \%$ para aterros controlados e $29 \%$ para lixões (vazadouros). A questão do destino correto de resíduos precisa ser discutida, pois evidencia a relação entre o meio ambiente e a saúde pública no Brasil. Esse tem sido um dos principais desafios enfrentados pelas administrações públicas brasileiras. E além disso merece atenção porque é desconhecido pela população, o que gera pouca pressão por parte da mesma.

Companhia Ambiental do Estado de São Paulo (CETESB) desenvolveu um instrumento chamado Índice de Qualidade de Aterros de Resíduos (IQR), que busca a partir de um questionário padronizado, avaliar as condições gerais do sistema de destinação final de resíduos, desde a escolha do local até suas condições técnicas operacionais. Sendo este amplamente utilizado no Estado de São Paulo desde de 1997.

Este trabalho tem por objetivo realizar avaliação da qualidade dos aspectos gerais de funcionamento e operação da área de disposição de resíduos sólidos de Goiânia, e descobrir se este está cumprindo legalmente com suas funções e em que grau de adequabilidade se encontra. 


\section{Materiais e Métodos}

Área de Estudo

A área de estudo (Figura 1) encontra-se localizado entre as coordenadas $16^{\circ} 38^{\prime}$ 53 " S e $49^{\circ} 21^{\prime} 56^{\prime \prime} \mathrm{W}$, no município de Goiânia, com uma área total de 733,116 km². O município possui uma população estimada em 1.412.364 habitantes (IBGE, 2014). Produz cerca de 3,2 toneladas de lixo por dia, estando em $4^{\circ}$ lugar no ranking nacional, atrás apenas de São Paulo, Rio de Janeiro e Belo Horizonte (IBGE, 2000).

Goiânia conta com um aterro sanitário localizado na região noroeste da cidade, com uma área total de $451.000 \mathrm{~m}^{2}$. As deposições de lixo no aterro tiveram início a partir de 1983, sendo o local caracterizado primeiramente como sendo um lixão, pois o lixo era diretamente depositado sobre o solo sem nenhuma impermeabilização. Somente dez anos depois que viria a se tornar um aterro sanitário (SENA et al, 2012, pg.2).

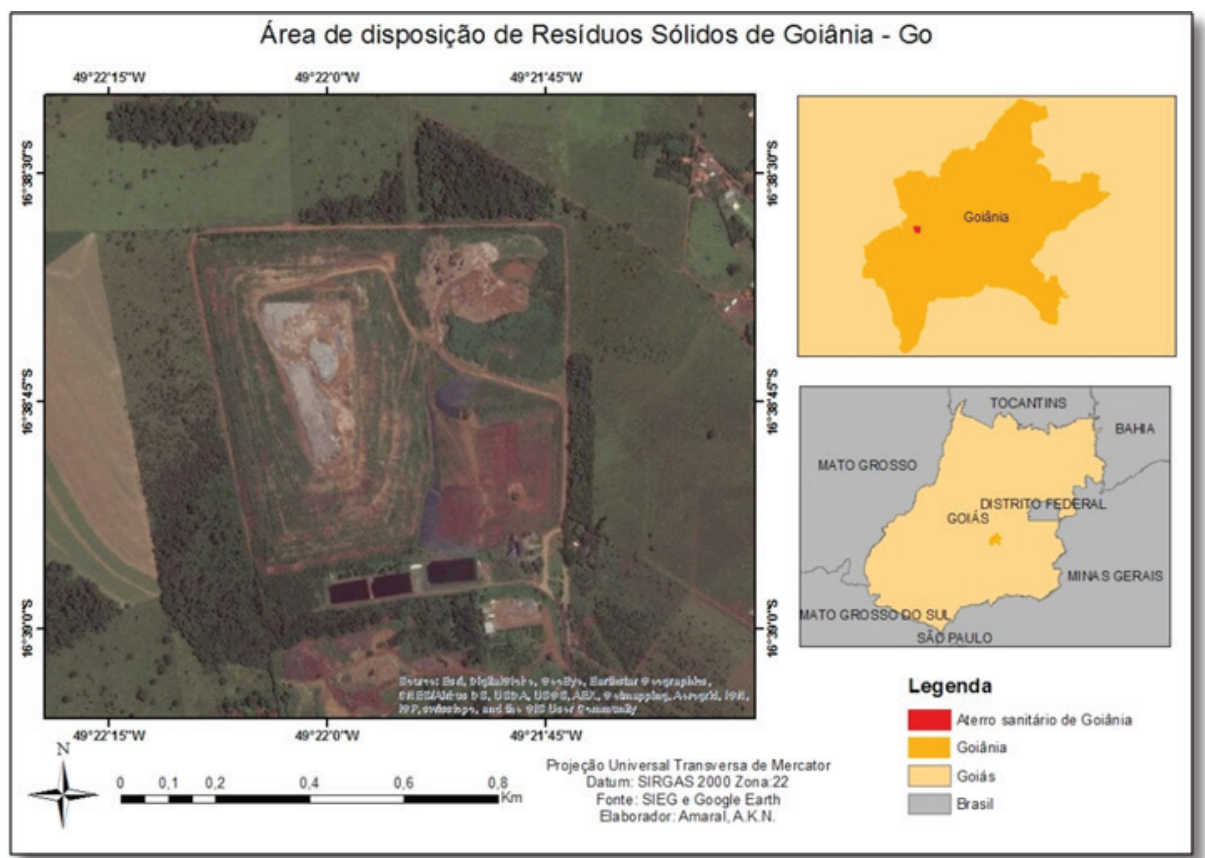

Figura 1. Mapa de Localização da área de disposição de resíduos sólidos de Goiânia.

\section{Procedimentos Metodológicos}

Para a coleta de dados foram feitas três visitas ao local, onde foram coletadas informações in loco para o preenchimento do questionário e para obtenção de fotos do local, além de uma entrevista com o responsável pelo aterro. 
Para a avaliação do aterro foi utilizado o IQR, metodologia proposta CETESB, que consta em preencher um questionário padronizado, "check list", que leva em consideração três parâmetros: características do local, infraestrutura e condições operacionais (CETESB, 2007). Para apuração do IQR é feita a soma das pontuações obtidas dos três componentes, características do local (Fórmula 1), infraestrutura implantada e condições operacionais, e logo depois a divisão desse resultado por 13 .

Fórmula da equação do IQR:

$$
\mathbf{I Q R}=\underline{\text { Subtotal } 1+\text { Subtotal } 2+\text { Subtotal } 3}
$$

De acordo com os resultados obtidos os mesmos são classificados qualitativamente conforme os itens descritos no quadro 1.

Quadro 1. Enquadramento das instalações e dos sistemas de disposição final de resíduos sólidos.

\begin{tabular}{|c|c|}
\hline Intervalos & Enquadramento \\
\hline 0,0 a 6,0 & Condições Inadequadas \\
\hline 6,1 a 8,0 & Condições Controladas \\
\hline 8,1 a 10 & Condições Adequadas \\
\hline
\end{tabular}

São considerados aterros adequados os que possuem uma destinação dos resíduos sólidos e que cumprem com todos ou a maior parte dos requisitos para o seu melhor funcionamento; os que apresentam condições controladas, podem ser definidos como aqueles que buscam cumprir com a maior parte dos requisitos mas que ainda tem alguns itens que se encontram irregulares; e os que apresentam condições inadequadas são aqueles que não cumprem com a maior parte de suas obrigações, perdendo suas características de "aterro sanitário" e passando para "aterro controlado".

\section{Resultados e Discussões}

\section{Resíduos Sólidos em Goiânia}

Quem cuida da coleta, deposição de resíduos sólidos e sua gestão atualmente no município de Goiânia é a COMURG, desde de 2008. Segundo a Resolução COMURG N 20 de 07/06/2016, o aterro sanitário de Goiânia recebe apenas resíduos sólidos classificados pela ABNT NBR 10.004/2004 como Classe II - não perigosos, que não sejam Recicláveis e/ou Reaproveitáveis. Os resíduos sólidos domiciliares e públicos (RSDO e RSPU), são recolhidos sem cobrança extra caso estes não ultrapassem os 200 litros/dia, estando cobertos pelo Imposto Predial Territorial Urbano (IPTU). Os Resíduos de Construção Civil (RCC) de Saúde (RSS) e de Mata Verde (Galhadas) não são coletados pela Companhia de Urbanização de Goiânia (COMURG), devendo o responsável contratar empresas particulares que prestem esse serviço, e realizar o pagamento da guia para efetuar o descarte no local. 
Em 2011 foi feito pela COMURG, por meio de uma solicitação de manifestação de interesse PMI No 001/2013, a caracterização dos resíduos domiciliares do município de Goiânia, através da amostragem dos resíduos em alguns bairros. A partir deste foi possível obter o conhecimento das características dos resíduos produzidos pela população. Na Figura 2 é apresentado o resultado deste estudo.

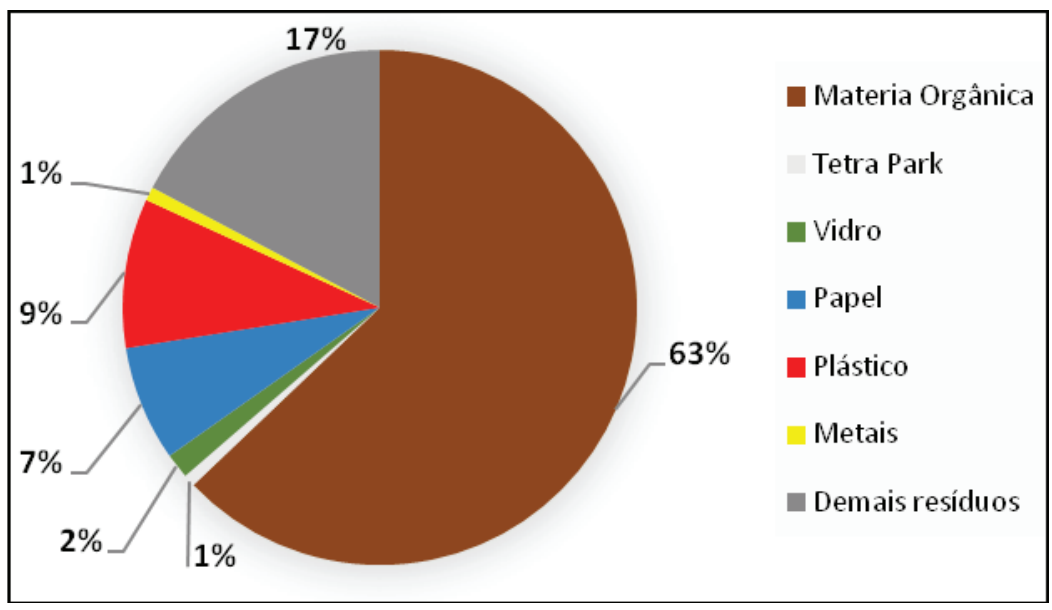

Figura 2. Composição geral dos resíduos domiciliares coletados no município. Fonte: PMI, 001/2013.

A cidade passa por uma séria crise no gerenciamento de seus resíduos sólidos urbanos, onde é fartamente noticiada pela mídia local, mostrando diariamente reclamações da ausência de coletas, problemas na contratação de caminhões para o transporte e vários outros. No ano de 2012 o município de Goiânia teve um gasto de aproximadamente de R \$ 255 milhões na política pública de limpeza urbana, o que equivale uma média de R\$ 196,00 por habitante, enquanto a média nacional está em torno de R\$133,56 (MPGO, 2015).

O método utilizado para o funcionamento do aterro de Goiânia é o da área, que consiste na formação de camadas de resíduos compactados sobrepostas, acima do nível do terreno, o que resulta em maior quantidade de resíduo por área. "Este método é recomendado para uma área que não apresente boas condições de escavação, geralmente, locais planos em que o lençol freático é muito superficial" (FARIA, 2002, pg.93).

É possível observar que as características do local apresentam algumas irregularidades. Este mantém uma distância dos núcleos habitacionais menor que 500 metros, devido ao processo de expansão urbana da região, sendo que as áreas situadas nas adjacências além de já servirem à função de moradia de chacareiros, têm sido alvo de especulação imobiliária, visando à formação de novos loteamentos (SENA, 2012, pg.2).

Nas visitas ao local e como o auxílio de SIG, foi possível aferir que o recurso mais próximo ao aterro é o Córrego Caveirinha, que se encontra a uma distância que 
ultrapassa os 200 metros do aterro, como recomendado pela Portaria $\mathrm{n}^{\circ} 124$ de 20/08/80 do Ministério do Interior (Figura 3), onde apresenta um notável desmatamento. Em duas das três visitas feitas no local, foi possível encontrar caminhões captando água do córrego, para jorrar no aterro para decantar os sólidos suspensos provenientes da grande quantidade de maquinário presente na área (Figura 4).

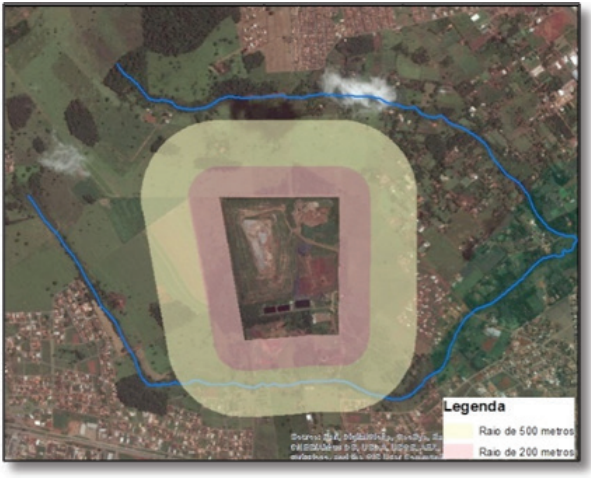

Figura 3. Raios de 200 e 500 metros da área do aterro.

Fonte: Google Earth.

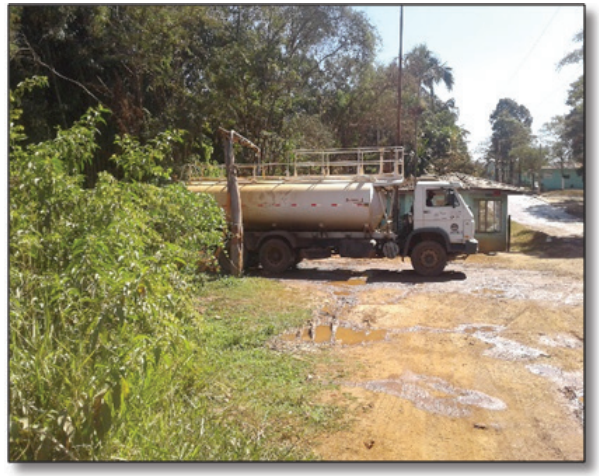

Figura 4. Caminhão captando água para aspergir no aterro. Fonte: Autor, 2015.

Segundo o Macrozoneamento Agroecológico e Econômico do Estado de Goiás (MACROZAEE) feito para o Estado Goiás em 2014, o solo da área é Latossolo, mas devido ao tamanho da escala (1:500 000) não ser compatível com a área em estudo, foi solicitado a equipe de operação do aterro informações acerca do solo do local. De acordo com as informações disponibilizadas o solo em seus primeiros 8 metros de profundidade possui textura argilosa, e a partir desta profundidade apresenta maior traço de silte. Foi disponibilizado também informações acerca do lençol freático, sendo este atingido em seus 20 metros de profundidade.

A presença de argila em solos profundos, o caracteriza como solos resistentes e com baixa atividade de percolação, apresentando assim barreiras para a contaminação do lençol freático (FERREIRA, 2014, pg. 3407). Sendo assim considerados aptos para certo tipo de atividades impactantes.

Conforme Santos et al (2013, pg. 5) e Pazzetto (2009, pg. 25) foi escolhido para determinar a permeabilidade dos solos da área por meio de um método indireto, devido à falta de recursos para assim realizar aferição mais condizente com a realidade. Foi escolhida a metodologia CAPUTO (1996), onde é possível inferir a permeabilidade dos solos com base na sua textura (Tabela 1). Sendo os solos de textura argilosa a siltosa, o coeficiente de permeabilidade está entre $<10^{-9}$ a $10^{-6}$, sendo considerado então de baixa permeabilidade. 
Tabela 1. Valores de coeficiente de permeabilidade $\mathrm{K}(\mathrm{m} / \mathrm{s})$.

\begin{tabular}{|c|c|}
\hline Fração de solo (Textura) & $\mathbf{K}(\mathbf{m} / \mathbf{s})$ \\
\hline Argilas & $<10^{-9}$ \\
\hline Siltes & $10^{-9} \mathrm{a} 10^{-6}$ \\
\hline Areias argilosas & $10^{-7}$ \\
\hline Areias Finas & $10^{-5}$ \\
\hline Areias Médias & $10^{-4}$ \\
\hline Areias Grossas & $10^{-3}$ \\
\hline
\end{tabular}

O material utilizado para o recobrimento dos resíduos é em sua maior parte, resíduos de construção de civil, sendo essa prática não recomendada a se tomar, uma vez que haja a falta de maquinário para executar as atividades de espalhamento e recobrimento.

A via de acesso ao aterro apresenta em boas condições, estando elas pavimentadas e sinalizadas. O transito no local é intenso devido a constante entrada de caminhões trazendo resíduos, o que gera grande quantidade de sólidos suspensos, o que é controlado com a aspersão de água na via. A área em sua grande parte está cercada pelo cinturão verde, ajudando assim no isolamento visual da vizinhança, mas devido ao grande aumento da deposição de resíduos e a especulação imobiliária no local, isso é quase inevitável.

Em 2012, segundo o MPGO (2012), 69\% dos aterros sanitários do Estado de Goiás não possuíam licença de funcionamento, estando o aterro de Goiânia incluso neste grupo. Até 2011 o aterro possuía licenciamento ambiental de funcionamento, entretanto, depois deste ano, a Agência Municipal do Meio Ambiente (AMMA) não renovou a licença, uma vez que possuía diversas irregularidades que põem em risco os trabalhadores, a população em geral e o meio ambiente.

Os resultados da avaliação da área de disposição de resíduos sólidos de Goiânia partir do IQR, em termos de características do local, podem ser mostrados no Quadro 2.

Quadro 2. Avaliação das características do local na área de disposição de resíduos sólidos de Goiânia.

\begin{tabular}{|l|c|c|c|}
\hline \multicolumn{4}{|c|}{ Características do local } \\
\hline \hline SUBITEM & AVALIAÇÃO & PESO & \multirow{2}{*}{ VALOR } \\
\hline \hline \multirow{2}{*}{ Capacidade de suporte } & Adequada & 5 & \multirow{2}{*}{5} \\
\cline { 2 - 3 } & Inadequada & 0 & \\
\hline \multirow{2}{*}{ Proximidade dos núcleos habitacionais } & Longe $>500 \mathrm{~m}$ & 5 & \multirow{2}{*}{0} \\
\cline { 2 - 3 } & Próximo & 0 & \\
\hline \multirow{2}{*}{ Proximidade de corpos d'água } & Longe> $>200 \mathrm{~m}$ & 3 & \multirow{2}{*}{3} \\
\cline { 2 - 3 } & Próximo & 0 & \\
\hline
\end{tabular}




\begin{tabular}{|c|c|c|c|}
\hline \multicolumn{4}{|c|}{ Características do local } \\
\hline SUBITEM & AVALIAÇÃO & PESO & VALOR \\
\hline \multirow{3}{*}{ Profundidade do lençol freático } & Maior de $3 \mathrm{~m}$ & 4 & \multirow{3}{*}{4} \\
\hline & De 1 a 3 m & 2 & \\
\hline & De 0 a $1 \mathrm{~m}$ & 0 & \\
\hline \multirow{3}{*}{ Permeabilidade do solo } & Baixa & 5 & \multirow{3}{*}{5} \\
\hline & Média & 2 & \\
\hline & Alta & 0 & \\
\hline \multirow{3}{*}{ Disponibilidade do material para recobrimento } & Suficiente & 4 & \multirow{3}{*}{2} \\
\hline & Insuficiente & 2 & \\
\hline & Nenhuma & 0 & \\
\hline \multirow{2}{*}{ Qualidade do material para recobrimento } & Boa & 2 & \multirow{2}{*}{0} \\
\hline & Ruim & 0 & \\
\hline \multirow{3}{*}{ Condição do sistema viário, trânsito e acesso } & Boas & 3 & \multirow{3}{*}{3} \\
\hline & Regulares & 2 & \\
\hline & Ruins & 0 & \\
\hline \multirow{2}{*}{ Isolamento visual da vizinhança } & Bom & 4 & \multirow{2}{*}{0} \\
\hline & Ruim & 0 & \\
\hline \multirow{2}{*}{ Legalização da localização } & Permitido & 5 & \multirow{2}{*}{0} \\
\hline & Proibido & 0 & \\
\hline \multicolumn{2}{|l|}{ Subtotal 1} & 40 & 22 \\
\hline
\end{tabular}

A área do aterro se encontra cercada devidamente, isolada cerca e também pelo cinturão verde, em boa parte da sua extensão, impedindo assim que animais e catadores adentre ao local. Possui portaria onde os responsáveis verificam o tipo resíduo, o nome da empresa de transporte, a placa do veículo e se preciso a guia de pagamento da taxa. Mas a frente está o local onde feito a pesagem dos resíduos, onde um funcionário também irá aferir se o resíduo que está sendo entregue está de acordo com a descrição do entregador. A área se encontra impermeabilizada com a manta Geomembrana de Polietileno de Alta Densidade (PEAD).

Para tratamento do chorume o aterro possui duas lagoas anaeróbicas, onde o líquido é levado por drenos horizontais tipo "Espinha de Peixe", que funcionam basicamente como tanques sépticos abertos, cuja a função principal é a remoção da matéria orgânica carbonácea. Segundo um dos responsáveis pela visita, o Gestor Ambiental Weber Lauro Dias as lagoas possuem 80 metros de comprimento e 40 metros de largura e 5 metros de profundidade, podendo receber em cada uma das lagoas cerca de 16000 litros (Figura 5). As vazões de percolado em épocas de seca ficam por volta de 6 litros/s mas em épocas chuvosas está já chegou a 25 litros/s. 
Possui também uma lagoa facultativa que são projetadas com o objetivo de remoção de DBO (Demanda Bioquímica de Oxigênio) tendo uma aplicação de cargas orgânicas menores que as anaeróbicas, está possui 100 metros de comprimento, 50 de largura e 5 metros de profundidade tendo está o volume de $25000 \mathrm{~m}^{3}$. Por falta de manutenção e operação adequada, as lagoas foram desativadas, funcionando apenas como meros depósitos de chorume (MPGO, 2015).

Parte do percolado gerado pelo aterro, é gerenciado em um ciclo fechado, ou seja, o resíduo (lodo) originado pelas lagoas de tratamento é retirado e depositado novamente no aterro através de bombas e caminhões, ajudando na decomposição dos resíduos orgânicos e depois novamente infiltrado para a lagoa. Outra parte é encaminhado a Estação de Tratamento de Esgoto (ETE) do Rio Meia Ponte - Dr. Seixo de Brito, localizada à $12 \mathrm{~km}$ do aterro. Segundo o MPGO (2015) esse transporte ocorre de forma irregular, uma vez que não possui autorização no arcabouço legislativo ambiental.

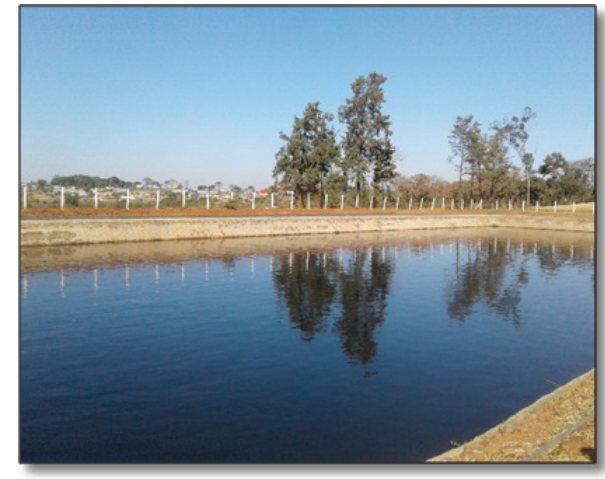

Figura 5. Lagoa Anaeróbica. Fonte: Autor, 2016.

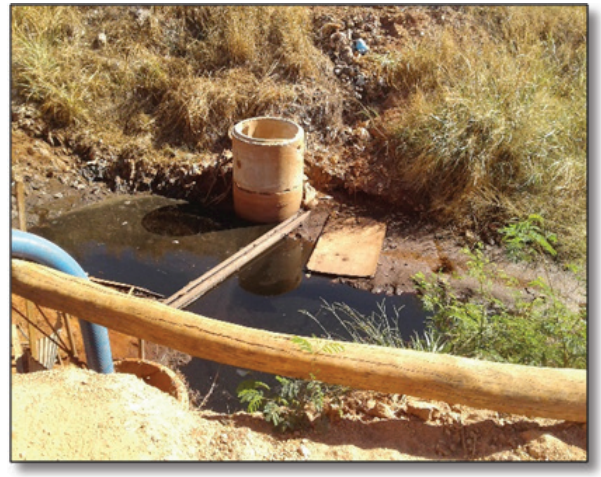

Figura 6. Lançamento de chorume em local Inadequado. Fonte: Autor,2016.

Em 2007 o MPGO (Ministério Público do Estado de Goiás) publica uma ação civil contra a empresa que administrava o aterro, Qualix Serviços Ambientais ltda. Um dos problemas apresentados na mesma mostra que a operação denominada "ciclo fechado" havia apresentando falhas, uma vez que o efluente gerado era maior que a capacidade de infiltração das lagoas, gerando assim um acúmulo de chorume em locais impróprios provocando sérios problemas ao meio ambiente e como a possibilidade de contaminação do solo e do lençol freático. Em uma das visitas ao local para a realização deste trabalho, foi identificado o acumulo inadequado de percolado em uma área próxima as lagoas, (Figura 6).

No local possui um sistema de drenagem águas pluviais definitivas, onde as águas são direcionadas da forma que não entre em contato com os resíduos e com as lagoas de tratamento (Figura 7). Não possui um sistema de drenagem de águas provisórias, sendo 
que em épocas chuvosas é grande a possibilidade que a lagoa transborde para áreas inadequadas, podendo assim contaminar o solo na área e o lençol freático.

Para o tratamento dos gases existe a drenagem vertical, que consiste em captar os gases por tubulações e os direcioná-los para atmosfera, evitando que esses gases infiltrem no subsolo e atinjam redes de esgoto, fossas e poços (Figura 8). Os gases liberados pela dissolução da matéria orgânica são compostos basicamente de metano $\left(\mathrm{CH}_{4}\right)$, dióxido de carbono $\left(\mathrm{CO}_{2}\right)$, nitrogênio $\left(\mathrm{N}_{2}\right)$, hidrogênio $\left(\mathrm{H}_{2}\right)$, oxigênio $\left(\mathrm{O}_{2}\right)$ e gás sulfídrico $\left(\mathrm{H}_{2} \mathrm{~S}\right)$, sendo que na maioria dos aterros sanitários apresentam concentração de metano acima de 55\% e de dióxido de carbono acima de 33\% (OKAMURA, 2013, pg.36 -37). Os gases liberados pelos aterros sanitários contribuem para o fenômeno conhecido como "efeito estufa", sendo o metano o mais prejudicial, poluindo 21 vezes mais que o dióxido de carbono. Todo o biogás produzido na área é queimado, para a mitigação dos efeitos causados na atmosfera, com a sua queima o biogás é transformado em dióxido de carbono e em vapor d'água.

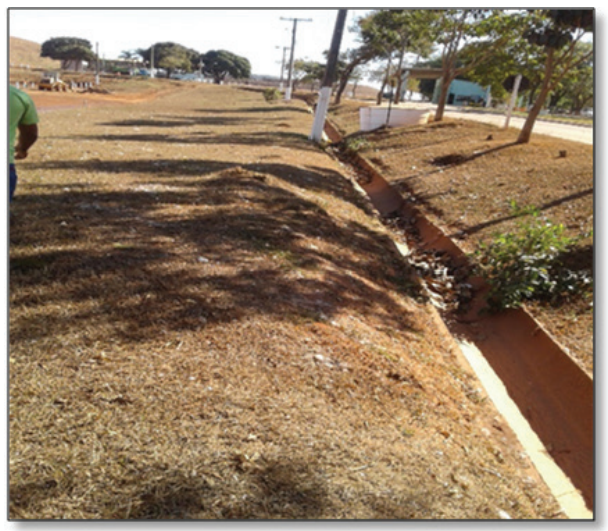

Figura 7. Dreno de águas pluviais. Fonte: Autor, 2016.

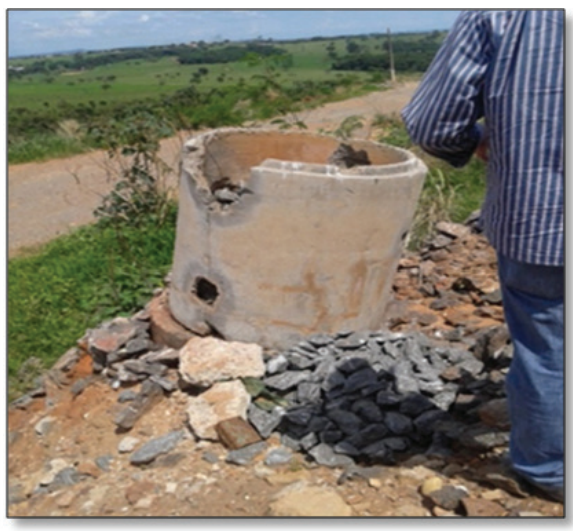

Figura 8. Tubulações para queima de gases. Fonte: Autor, 2015.

O aterro conta com vários equipamentos para a sua operação como, trator de esteira, pá carregadeira, escavadeira hidráulica, retroescavadeira, caminhão pipa e caminhão caçamba.

O monitoramento das águas subterrâneas segundo os responsáveis pelo aterro é feito de tempos em tempos. Foi disponibilizado pela equipe de operação do aterro um documento intitulado " $2^{\circ}$ Relatório de Monitoramento Ambiental" realizado pela empresa DBO Engenharia Ambiental no ano de 2012, neste foi executado análises como amostras de água subterrânea dos poços de monitoramento no ano 2012, onde foi possível determinar que em três pontos de coleta, apresentou valores de $\mathrm{P}$ (fósforo) e $\mathrm{Pb}$ (chumbo) acima do permitido de acordo com a resolução CONAMA 396/2008. Não foi disponibilizado e nem encontrado outro documento que afirme que essas coletas estão sendo realizadas na área atualmente. 
Os aspectos sobre a infraestrutura implantada no aterro são mostrados no Quadro 3.

Quadro 3: Avaliação da infraestrutura da área de disposição de resíduos sólidos de Goiânia.

\begin{tabular}{|c|c|c|c|}
\hline \multicolumn{4}{|c|}{ Infraestrutura Implantada } \\
\hline SUBITEM & AVALIAÇÃO & PESO & VALOR \\
\hline \multirow{2}{*}{ Cercamento da área } & Sim & 2 & \multirow{2}{*}{2} \\
\hline & Não & 0 & \\
\hline \multirow{2}{*}{ Portaria/Guarita } & Sim & 2 & \multirow{2}{*}{2} \\
\hline & Não & 0 & \\
\hline \multirow{2}{*}{ Impermeabilização de base } & Sim & 5 & \multirow{2}{*}{5} \\
\hline & Não & 0 & \\
\hline \multirow{3}{*}{ Drenagem do chorume } & Suficiente & 5 & \multirow{3}{*}{1} \\
\hline & Insuficiente & 1 & \\
\hline & Inexistente & 0 & \\
\hline \multirow{3}{*}{ Drenagem águas pluviais definitivas } & Suficiente & 4 & \multirow{3}{*}{4} \\
\hline & Insuficiente & 2 & \\
\hline & Inexistente & 0 & \\
\hline \multirow{3}{*}{ Drenagem águas pluviais provisórias } & Suficiente & 2 & \multirow{3}{*}{0} \\
\hline & Insuficiente & 1 & \\
\hline & Inexistente & 0 & \\
\hline \multirow{3}{*}{ Trator de esteira } & Permanente & 5 & \multirow{3}{*}{5} \\
\hline & Periodicamente & 2 & \\
\hline & Inexistente & 0 & \\
\hline \multirow{2}{*}{ Outros equipamentos } & Sim & 1 & \multirow{2}{*}{1} \\
\hline & Não & 0 & \\
\hline \multirow{2}{*}{ Sistema de tratamento de chorume } & Suficiente & 5 & \multirow{2}{*}{0} \\
\hline & Insuf./Inexist. & 0 & \\
\hline \multirow{2}{*}{ Acesso à frente do trabalho } & Bom & 3 & \multirow{2}{*}{3} \\
\hline & Ruim & 0 & \\
\hline \multirow{2}{*}{ Vigilantes } & Sim & 1 & \multirow{2}{*}{1} \\
\hline & Não & 0 & \\
\hline \multirow{3}{*}{ Drenagem de gases } & Suficiente & 3 & \multirow{3}{*}{1} \\
\hline & Insuficiente & 1 & \\
\hline & Inexistente & 0 & \\
\hline \multirow{2}{*}{ Controle de cargas } & Sim & 2 & \multirow{2}{*}{2} \\
\hline & Não & 0 & \\
\hline & Suficiente & 3 & \\
\hline Monitoramento de águas subterrâneas & Insuficiente & 2 & 2 \\
\hline & Inexistente & 0 & \\
\hline & Sim & 2 & \\
\hline Atendimento ao projeto & Parcialmente & 1 & 2 \\
\hline & Não & 0 & \\
\hline Subtotal 2 & & 45 & 31 \\
\hline
\end{tabular}


Nas visitas feitas ao local, não foi identificado a ocorrência de lixo descoberto, sendo eles cobertos diariamente por uma camada de solo juntamente com os resíduos de construção civil. Essa prática se desenvolvida de maneira correta, evita a propagação de vetores no local, o que foi perceptível no local. Foi encontrado a presença de Urubus, mas em pouca quantidade. No local por ser cercado não há a presença de catadores e nem de animais de criação.

Os resíduos de saúde em geral são sujeitados a passar por um tratamento antes de serem dispostos no aterro. Eles são acondicionados em um galpão e duas vezes na semana são levados para a o município de Ceilândia (DF) onde passam por uma espécie de triagem com a finalidade de impedir que os resíduos cheguem contaminados. Grande parte desses resíduos são incinerados e apenas as suas cinzas retornam e são lançadas ao aterro. Normalmente dois caminhões são suficientes no transporte (Figura 9).

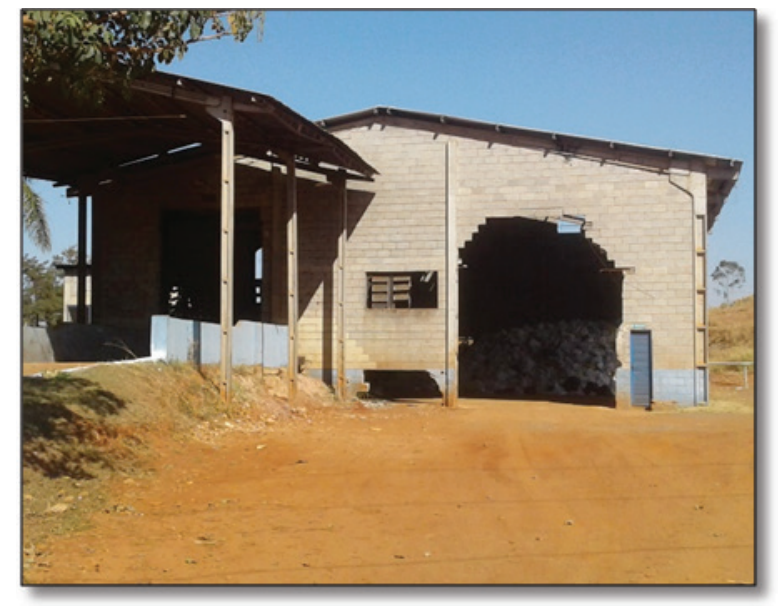

Figura 9. Galpão onde são condicionados os RSS. Fonte: Autor,2016.

São recebidos também resíduos industriais, sendo que as permissões de descarga destes só são concedidas feito análises comprovando a classificação dos resíduos como classe II de acordo com a norma ABNT - NBR 10.004/2004.

$\mathrm{O}$ funcionamento do sistema de drenagem pluvial definitiva se mostra eficiente por conta das suas instalações, já a provisória o aterro não possui, sendo este sistema ineficiente em épocas chuvosas. O funcionamento do sistema de drenagem de chorume não se apresenta em boas condições pelo fato de ter sido encontrado acumulação de chorume em locais inapropriados, o que leva a deduzir que o sistema de drenagem de chorume em vigência não é suficiente.

Em relação às condições operacionais no aterro, os resultados são mostrados no Quadro 4. 
Quadro 4: Condições operacionais da área de disposição de resíduos sólidos de Goiânia.

\begin{tabular}{|c|c|c|c|}
\hline \multicolumn{4}{|c|}{ Condições operacionais } \\
\hline SUBITEM & AVALIAÇÃO & PESO & VALOR \\
\hline \multirow{2}{*}{ Aspecto Geral } & Bom & 4 & \multirow{2}{*}{4} \\
\hline & Ruim & 0 & \\
\hline \multirow{2}{*}{ Ocorrência de lixo a descoberto } & Não & 4 & \multirow{2}{*}{4} \\
\hline & Sim & 0 & \\
\hline \multirow{3}{*}{ Recobrimento do Lixo } & Adequado & 4 & \multirow{3}{*}{1} \\
\hline & Inadequado & 1 & \\
\hline & Inexistente & 0 & \\
\hline \multirow{2}{*}{ Presença de Urubus ou Gaivotas } & Não & 1 & \multirow{2}{*}{0} \\
\hline & Sim & 0 & \\
\hline \multirow{2}{*}{ Presença de moscas em grande quantidade } & Não & 2 & \multirow{2}{*}{2} \\
\hline & Sim & 0 & \\
\hline \multirow{2}{*}{ Presença de catadores } & Não & 3 & \multirow{2}{*}{3} \\
\hline & Sim & 0 & \\
\hline \multirow{2}{*}{ Criação de animais (porcos, bois) } & Não & 3 & \multirow{2}{*}{3} \\
\hline & Sim & 0 & \\
\hline \multirow{2}{*}{ Descarga de resíduos de serviço de saúde } & Não & 3 & \multirow{2}{*}{0} \\
\hline & Sim & 0 & \\
\hline \multirow{2}{*}{ Descarga de resíduos industriais } & Não & 4 & \multirow{2}{*}{0} \\
\hline & Sim & 0 & \\
\hline \multirow{3}{*}{$\begin{array}{l}\text { Funcionamento do sistema de drenagem } \\
\text { pluvial definitiva }\end{array}$} & Bom & 2 & \multirow{3}{*}{1} \\
\hline & Regular & 1 & \\
\hline & Inexistente & 0 & \\
\hline \multirow{3}{*}{$\begin{array}{l}\text { Funcionamento do sistema de drenagem } \\
\text { pluvial provisória }\end{array}$} & Bom & 2 & \multirow{3}{*}{0} \\
\hline & Regular & 1 & \\
\hline & Inexistente & 0 & \\
\hline \multirow{3}{*}{$\begin{array}{l}\text { Funcionamento do sistema de drenagem } \\
\text { pluvial de chorume }\end{array}$} & Bom & 3 & \multirow{3}{*}{2} \\
\hline & Regular & 2 & \\
\hline & Inexistente & 0 & \\
\hline \multirow{3}{*}{$\begin{array}{l}\text { Funcionamento do Sistema de tratamento } \\
\text { do chorume }\end{array}$} & Bom & 5 & \multirow{3}{*}{2} \\
\hline & Regular & 2 & \\
\hline & Inexistente & 0 & \\
\hline \multirow{2}{*}{ Eficiência da vigilância } & Bom & 1 & 1 \\
\hline & Ruim & 0 & 1 \\
\hline & Boas & 2 & \\
\hline Manutenção dos acessos internos & Regulares & 1 & 2 \\
\hline & Ruins & 0 & \\
\hline Subtotal 3 & & 45 & 25 \\
\hline
\end{tabular}


Através dos três parâmetros obtidos foi possível calcular o IQR da área de disposição final de resíduos sólidos do município de Goiânia - GO.

$$
\begin{aligned}
& \mathrm{IQR}=(\mathrm{SUB} 1+\mathrm{SUB} 2+\mathrm{SUB} 3) / 13 \\
& \mathrm{IQR}=(22+31+25) / 13 \\
& \mathrm{IQR}=6,00
\end{aligned}
$$

O valor do IQR obtido foi de 6,00 demostrando que as condições da área, quanto a características, infraestrutura e operacionalidade, estão em desacordo com a legislação, não possuindo as características essenciais para ser considerado um "Aterro Sanitário".

\section{Considerações finais}

Com base na metodologia aplicada, foi possível ter uma visão mais ampla da situação da área de disposição de resíduos de Goiânia, podendo assim pontuar alguns itens.

No tópico de características do local, foi possível observar que o aterro está localizado em uma área inapropriada, uma vez que ao menos possui licença de funcionamento, sendo que apenas de $55 \%$ dos itens receberam uma pontuação de adequada ou regular. Sua proximidade dos núcleos habitacionais pode também causar grandes transtorno para a população ao redor, causando incômodos por conta do mau cheiro e pela proliferação de vetores.

Quanto a infraestrutura implantada os resultados foram pouco mais satisfatórios, possuindo $68,8 \%$ da pontuação positiva ou regular. Os itens que receberam a menor pontuação foram, as drenagens das águas pluviais provisórias, sistema de tratamento de chorume e monitoramento de águas subterrâneas, sendo esses um dos instrumentos utilizados para a prevenção e o controle de impactos gerados pelo local, uma vez que o não funcionando destes como deveria deixam a área mais vulnerável a sofrer impactos.

Nas condições operacionais os itens que receberam menor pontuação foram, presença de urubus e gaivota, descarga de resíduos de serviço de saúde e funcionamento do sistema de drenagem pluvial provisória. Dando destaque a descarga de resíduos de saúde, podendo ser este o mais contaminante de todos os resíduos recebidos pelo aterro, deve-se dar uma atenção maior pelo fato ser um resíduo contaminado, e se não despejado de maneira adequada pode causar a contaminação dos trabalhadores da área e se proliferar pelas aves que rodeiam o lugar. A maneira como está sendo gerenciado esse resíduo pode não ser a mais adequada, mas provisoriamente pode ser uma solução para se evitar uma possível contaminação.

$\mathrm{O}$ aterro sanitário se enquadrado de forma adequada, regulado conforme a lei é a melhor maneira de minimizar os impactos ambientais. Infelizmente, não é o caso do aterro de Goiânia, onde os resultados obtidos foram baixos e insatisfatórios, promovendo este às características de um "Aterro Controlado". 


\section{Agradecimentos}

À Universidade Federal de Goiás (UFG) que nos proporcionou os laboratórios para que essa pesquisa fosse desenvolvida, a professora Dr. Noely Vicente Ribeiro pelas orientações e aos colegas de graduação Lorrany Moisés Dutra e Maycon da Penha Silva pela ajuda nas visitas de campo. E em especial a Deus que tem nos dado capacidade de adquirir cada vez mais conhecimento.

\section{Referências}

ABNT - Associação Brasileira de Normas Técnicas. ABNT NBR 10004. Resíduos Sólidos - Classificação, 2004.

ABRELPE - Associação Brasileira de Empresas de Limpeza Pública e Resíduos Especiais. Panorama de Resíduos Sólidos no Brasil. 2012. São Paulo: Abrelpe, 2012.

ARAUJO, Paulo Jardel et al. Gerenciamento de resíduos sólidos dos shoppings de Aracaju. Caderno de Graduação-Ciências Exatas e Tecnológicas-UNIT, v. 2, n. 1, p. 33-44, 2014.

BRASIL. Decreto $n^{\circ} 7404$ de 23 de dezembro de 2010. Regulamenta a Lei $\mathrm{n}^{\circ}$ 12.305, de 2 de agosto de 2010, que institui a Política Nacional de Resíduos Sólidos. Poder Executivo, Brasília, DF, 23 dez. 2010. Disponível em: <http://www.planalto.gov.br/ ccivil_03/_ato2007-2010/2010/Decreto/D7404.htm>. Acesso em: 19 jan. 2015.

CETESB - Companhia Ambiental do Estado de São Paulo. Inventario estadual de resíduos sólidos domiciliares: relatório de 2007. São Paulo: CETESB, 2008. 6p. Disponível em: $<$ http://www.cetesb.sp.gov.br/solo/publicacoes-e-relatorios/1-publicacoes-/-relatorios>. Acesso em: 20 fev. 2015.

ELK, A. G. H. P. van. Mecanismos de Desenvolvimento Limpo Aplicado aos Resíduos Sólidos: Redução de Emissões na Disposição Final. Rio de Janeiro: IBAM, 2007.p.13.

FARIA, Flávia dos Santos. Índice da Qualidade de Aterros de Resíduos Urbanos. 2002, 355 p. Dissertação (Mestrado em Engenharia Civil). - COPPE, Universidade Federal do Rio de Janeiro. Rio de Janeiro, 2002. p.93.

FERREIRA, E. M.; CRUVINEL, KAS; COSTA, E. S. Disposição final dos resíduos sólidos urbanos: diagnóstico da gestão do município de Santo Antônio de Goiás. Revista Monografias Ambientais, Santa Maria, v. 14, n. 3, p. 3401-3411, 2014.

IBGE - Instituto Brasileiro de Geografia e Estatística. Cidades. Disponível em: $<$ http:// www.cidades.ibge.gov.br/xtras/perfil.php?lang=\&codmun=520870\&search=goias/goia nia>. Acesso em: 25 fev. 2015.

IBGE - Instituto Brasileiro de Geografia e Estatística. Quantidade diária de lixo coletado, por unidade de destino final do lixo coletado, segundo as Grandes Regiões, Unidades da Federação, Regiões Metropolitanas e Municípios das Capitais - 2000. Disponível em: <www.ibge.gov.br/home/estatistica/populacao/condicaodevida/pnsb/lixo_coletado/ lixo_coletado110.shtm>. Acesso em: 25 fev. 2015. 
RESOLUÇÃO COMURG No 20 de 07/06/2016. Normatização para a disposição de resíduos no aterro sanitário de Goiânia. Disponível em: <https://www.legisweb.com.br/ legislacao/?id=324961>. Acesso em: 01 agosto. 2016

MACROZAEE - Macrozoneamento Agroecológico e Econômico do Estado de Goiás. Santos; Castro; 2014.Org.

MMA - Ministério do Meio Ambiente. Política de Resíduos Sólidos Apresenta Resultado em 4 Anos. Brasília: MMA, 05 ago. 2014. Disponível em: <http://www.mma. gov.br/informma/item/10272-pol\%C3\%ADtica-de-res\%C3\%ADduos s\%C3\%B3lidosapresenta-resultados-em-4-anos>. Acesso em: 01 fev. 2015.

MINTER - Ministério do Interior. Portaria $n^{\circ} 124$ de 20 de agosto de 1980. Disponível em: $<$ http://ima.al.gov.br/wp-content/uploads/2015/03/Portaria-nb0-124.80.pdf $>$. Acesso em: 04 agosto.2016.

MONTEIRO, José H. P.et al. Manual de Gerenciamento Integrado de Resíduos Sólidos. Rio de Janeiro: IBAM, p.149-151. 2001.

MPGO - Ministério Público do Estado de Goiás. Gestão à Vista: Percentual de Municípios com Aterro em 2009. Disponível em: <www.mpgo.mp.br/portalweb/hp/33/ docs/percentual_de_municipios_com_aterro_sanitario.pdf $>$._Acesso em: $01 \mathrm{fev} .2015$.

MPGO-Ministério Público do Estado de Goiás. Núcleo de Defesa do Meio Ambiente, Ação Pública Ambiental. Goiânia, 2015. p.6-17. Disponível em: <http://www.mpgo.mp.br/ portal/arquivos/2015/03/09/16_43_02_173_ACP_ATERRO_SANIT\%C3\%81RIO_ GOI\%C3\%82NIA.pdf > Acesso em: 10 mar. 2015.

MPGO - Ministério Público do Estado de Goiás. Gestão à Vista: Situação das Licenças de Aterros Sanitários nos Municípios Goianos. 2012. Disponível em: <http://www. mpgo.mp.br/portal/arquivos/2013/06/18/16_20_01_180_Situa\%C3\%A7\%C3\%A3o_ das_Licen\%C3\%A7as_de_Aterros_Sanit\% 30 \%A 1 rios_nos_Munic\%C3\%ADpios_ Goianos.pdf $>$. Acesso em: 18 fev. 2015.

MPGO - Ministério Público do Estado de Goiás. Núcleo de Defesa do Meio Ambiente. Ação civil pública com pedido de liminar. Goiânia, 2007. Disponível em: <http://www. $\mathrm{mp}$.go.gov.br/portalweb/hp/1/docs/acp_maguito_vilela_lixo.pdf $>$. Acesso em: $10 \mathrm{mar}$. 2015.

MUÑOZ, Susana Inés Segura. Impacto ambiental na área do aterro sanitário e incinerador de resíduos sólidos de ribeirão preto, SP: Avaliação dos níveis de metais pesados. Tese de Doutorado. UNIVERSIDADE DE SÃO PAULO. 2002.

OKAMURA, Layssa Aline et al. Avaliação e melhoria do poder calorifico de biogás proveniente de resíduos sólidos urbanos. Defesa em: 23 de março de 2013. Dissertação. (Mestrado em Ciências Ambientais) - Universidade Tecnológica Federal do Paraná, Campus Curitiba, 2013.

SANTOS, Antonio Lázaro Ferreira; HARAGUCHI, M. T.; LEITÃO, G. C. Índice de qualidade de aterro de resíduos (IQR) como subsidio para avaliar o sistema de disposição final do município de Anápolis-GO. Scientia plena, v. 8, n. 10, 2013. 
SENA, Cristiane Pereira. et al. Análise sócio-econômico-ambiental da ocupação antrópica do entorno do aterro sanitário de Goiânia. $3^{\circ}$ Congresso Internacional de Tecnologias para o Meio Ambiente, RS, 2p. 2012. Disponível em: < http://www.proamb. com.br/downloads/p86our.pdf > . Acesso em 16 fev. 2015.

PAZZETTO, Morgane Brogni et al. Estudo da Permeabilidade de Solos Argilosos Disponíveis Para Recuperação de Áreas Degradadas Pela Mineração de Carvão No Sul De Santa Catarina. 2009.

PMI - Procedimento de Manifestação de Interesse. PMI 001/2013. Goiânia, 2013. Disponível em: < http://www.goiania.go.gov.br/download/licitacao/interesse/mi130001 edital.pdf $>$. Acesso em: 25/01/2016.

SERRA, V.; GROSSI, M.; PIMENTEL, V. Lixão, aterro controlado e aterro sanitário. Botucatu, SP: Departamento de Química e Bioquímica. UNESP. Botucatu. S.P., Brasil, 1998.

\section{Ana Karolyna Nunes Amaral}

Graduada em Ciências Ambientais pela Universidade Federal de Goiás, onde atualmente é mestranda pelo Programa de Pós-Graduação em Ciências Ambientais.

Campus Samambaia, 74001970 - Goiânia, GO. Caixa-postal: 131.

E-mail: karocana@hotmail.com

Frederick Douglas Rodrigues Costa

Graduando do curso de Ciências Biológicas pela Universidade Federal de Goiás Campus Samambaia, 74001970 - Goiânia, GO. Caixa-postal: 131.

E-mail: frederick1douglas@gmail.com

\section{NoEly Vicente Ribeiro}

Professora titular do Instituto de Estudos Socioambientais da Universidade Federal de Goiás. Possui graduação em Engenharia Cartográfica pela Universidade Estadual Paulista Júlio de Mesquita Filho - UNESP, Especialização em Geoprocessamento pela Universidade de Brasília - UNB e Doutorado em Geografia pela Universidade Federal de Goiás - UFG.

Campus Samambaia, 74001970 - Goiânia, GO. Caixa-postal: 131.

E-mail: noely.ribeiro@uol.com.br

Recebido para publicação em fevereiro de 2016 Aprovado para publicação em julho de 2016 